\title{
Vitamins B6, Folic Acid, and B12: Molecular Functions and Prevalence of Deficiency in India
}

\author{
M SIVAPRASAD, T SHALINI, SHAYARI DAS, V VIJAYALAKSHMI and G BHANUPRAKASH \\ REDDY* \\ National Institute of Nutrition, Jamai-Osmania, Tarnaka, Hyderabad 500 007, India
}

(Received on 07 July 2016; Accepted on 16 August 2016)

\begin{abstract}
Vitamin B6 (B6), folate, and vitamin B12 (B12) are essential right from the inception of life as important players in numerous biochemical and molecular functions. They are interdependent, and deficiency of one of them is likely to influence the metabolism of the other. B6 is involved in numerous reactions such as synthesis of neurotransmitters, histamines, and haemoglobin; and transamination, and decarboxylation reactions. Recent studies have revealed the role of B6 in various non-enzymatic reactions as an antioxidant, carbonyl scavenger, metal chelator, and antiglycating agent. Folate plays a pivotal role due to its involvement in the synthesis of precursors of DNA and RNA, methylation reactions and metabolism of some amino acids. B6 along with folate and B12 play a crucial role in the network of one-carbon metabolism, which governs a myriad of functions in the body. Suboptimal B6 status is associated with various diseases. Impaired folate status is implicated in various chronic diseases including megaloblastic anaemia, neural tube defects, cardiovascular diseases, cancer and neurological problems. Low intake of B12 results in methylmalonic aciduria leading to neurological problems and also megaloblastic anaemia. Reports on the prevalence of B6 deficiency are scarce in India. The majority of the studies on folate and B12 deficiencies are focused on categories of the population such as elderly people, pregnant women, and children. In other cases, studies on folate and B12 were carried out in connection with some disease conditions such as cognitive dysfunction, anaemia, low birth weight and maternal nutrition. The molecular functions of these vitamins and studies on the prevalence of deficiency of these vitamins in India have been summarized in this review.
\end{abstract}

Keywords: Pyridoxal Phosphate; Pyridoxamine; Transamination; Folate; Cobalamin; Methylmalonic Acid; One-Carbon Metabolism; Methionine; Homocysteine; Neural Tube Defects; Anaemia

\section{Vitamin B6}

Paul Gyorgy discovered vitamin B6 (B6) as the cure for 'rat acrodynia' in 1934. B6 is a pyridine derivative, 3-hydroxy-4,5-dihydroxy-methyl-2-methylpyridine (Rosenberg, 2012). It comprises of three vitamers that are interconvertible in vivo [pyridoxine $(\mathrm{PN}) \Leftrightarrow$ pyridoxal (PL) $\Leftrightarrow$ pyridoxamine (PM)] (Fig. 1). They differ in the variable group present in the 4-position (Wu and Lu, 2012). These three derivatives undergo phosphorylation in the liver to generate pyridoxine phosphate (PNP), pyridoxal phosphate (PLP) and pyridoxamine phosphate (PMP) to act as cofactors (Fig. 1). B6 is involved in more than 100 enzymatic reactions participating in diverse and far-reaching metabolic pathways (Wu and Lu, 2012).

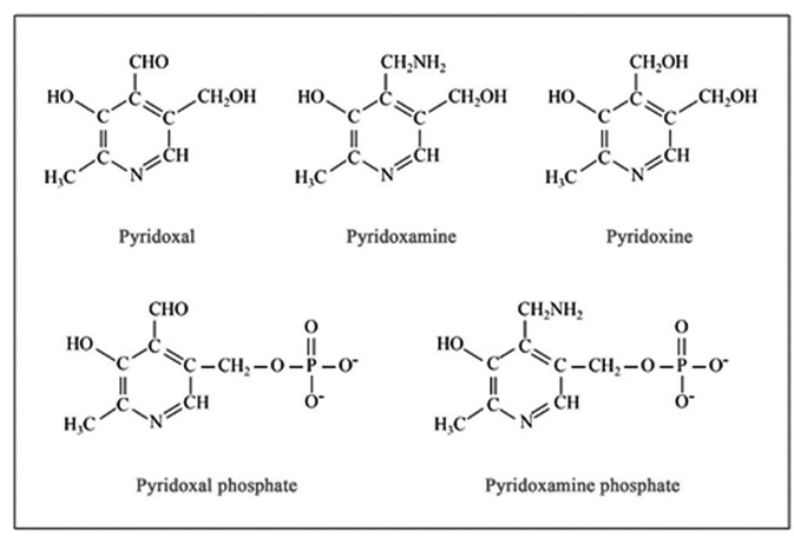

Fig. 1: Structure of different forms of vitamin B6 (Source: (Lakshmiah et al., 2016); with permission from the Oxford \& IBH Publishing Co Pvt Ltd)

*Author for Correspondence: E-mail: geereddy@yahoo.com; bhanu@icmr.org.in 


\section{Dietary Sources, Requirement, and Deficiency}

Bacteria, fungi, and plants can synthesize B6 whereas most of the animals including humans lack this ability and hence depend on an external source. Organ meats, vegetables, whole grains, sunflower seeds, bananas, beans, mushroom and nuts like pistachios are excellent sources (Clase et al., 2013). Animal products contain PLP and PMP as major forms while the usual form in plants and cereals is PN, PNP, and PN glucoside which is less bioavailable (Stanger, 2012). Hence, vegetarians and vegans are at higher risk of developing B6 deficiency. Dietary requirements of B6 are mentioned in Table 1. Severe or isolated B6 deficiency is rare in the general scenario. The inadequacy of B6 is however linked to the deficiency of other B vitamins (McCormick, 2006). Renal problems, malabsorption syndromes (Celiac disease, Crohn's disease, and ulcerative colitis), genetic diseases (homocystinuria) and antiepileptic drugs can cause B6 deficiency (Mackey et al., 2005; McCormick, 2006).

\section{Absorption and Transportation}

B6 compounds are absorbed in the dephosphorylated form in jejunum and ileum by passive diffusion. Intestinal alkaline phosphatases are involved in dephosphorylation. Absorption is followed by its appearance in the liver to be converted to PLP. In the plasma about $60 \%$ of B6 is PLP which is bound to proteins. PL and PLP are primarily associated with plasma albumin. Though widely distributed in the tissues, storage of B6 in the body is minimal. Muscle is the major body store (70-80\%) of the vitamin. The major urinary metabolite of B6 is 4 pyridoxic acid (Lakshmiah et al., 2016). Absorption of B6 is decreased in patients taking isoniazid, in gastrointestinal diseases and due to irradiation. Also, $30-45 \%$ loss has been reported during cooking.

\section{Molecular Functions}

B6 is involved in a variety of roles which include synthesis of neurotransmitters, histamines, and haemoglobin; gene expression, transamination, decarboxylation, racemization, and elimination. (Clase et al., 2013). Recent studies have revealed the role of B6-vitamers in various non-enzymatic reactions as antioxidants, carbonyl scavengers, metal chelators, antiglycating agents and photosensitizers (Wondrak and Jacobson, 2012).

\section{Coenzyme Functions}

PLP participates as a cofactor in more than 100 enzymatic reactions in the body which include transamination, decarboxylation, desulphuration, carbohydrate and lipid metabolism; synthesis of neurotransmitters, histamines, and haemoglobin. B6 plays a crucial role in the one-carbon metabolism (Fig. 2). The isozymes of serine hydroxymethyltransferase (SHMT2 and SHMT1) present in mitochondria and cytoplasm require PLP as a cofactor for the de novo thymidylate biosynthesis. Cystathionine synthase uses PLP as a cofactor for the $\beta$-replacement of the hydroxyl group of L-serine by the thiolate group of homocysteine (Hcys) leading to the formation of cystathionine. PLP aids in the transfer of a methyl group from betaine $(\mathrm{N}, \mathrm{N}, \mathrm{N}$ - trimethylglycine) to homocysteine (Hcys), leading to the formation of dimethylglycine and methionine which is catalysed by betaine-Hcys methyltransferase (BHMT) (Wu and $\mathrm{Lu}, 2012)$.

Table 1: Dietary requirement of B6, folate, and B12 for various physiological groups $* 1 \mu \mathrm{g}$ of food folate $=0.5 \mu \mathrm{g}$ of synthetic folic acid taken on an empty stomach and $0.6 \mu \mathrm{g}$ folic acid taken with meals

\begin{tabular}{lllll}
\hline Group & Category/Age & B6 $(\mathrm{mg} / \mathrm{day})$ & Folate $(\mu \mathrm{g} / \mathrm{day} *)$ & B12 $(\mu \mathrm{g} / \mathrm{day})$ \\
\hline Men & Sedentary, moderate, heavy & 2.0 & 200 & 1.0 \\
Women & Sedentary, moderate, heavy & 2.0 & 200 & 1.0 \\
& Pregnant & 2.5 & 500 & 1.2 \\
& Lactating [0-12 months] & 2.5 & 300 & 1.5 \\
Infants & $0-12$ months & $0.1-0.4$ & 25 & 0.2 \\
Children & $1-9$ years & $0.9-1.6$ & $80-120$ & $0.2-1.0$ \\
Boys and Girls & $10-17$ years & $1.6-2.0$ & $140-200$ & - \\
\hline
\end{tabular}

Source (ICMR, 2010) 


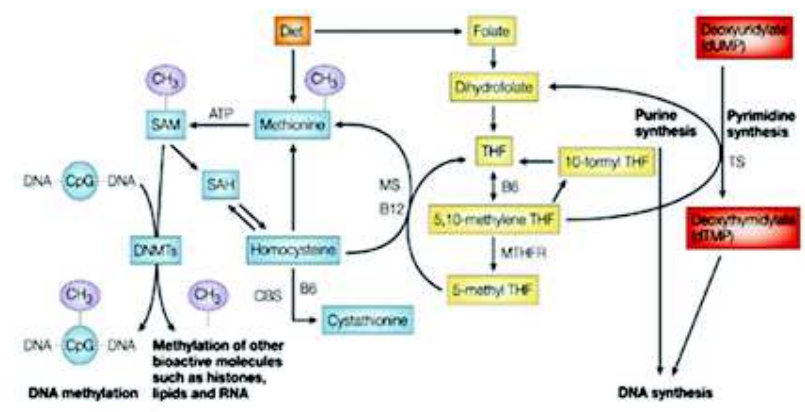

Fig. 2: Network of one-carbon metabolism (Adopted from (Lamprecht and Lipkin, 2003) with permission from the Nature Publishing Group)

\section{Non-enzymatic Functions}

The presence of phenolic hydroxyl group in the 3position of the pyridine ring imparts spontaneous redox reactivity. Hence, B6 acts as a potent antioxidant against free radicals (Wondrak and Jacobson, 2012). Amongst the three co-enzymatic forms, PLP elicits potent antioxidant functions. Free and inadequately chelated transition metal ions participate in metalcatalyzed peroxide decay (Fenton reaction), lipid peroxidation, and other redox processes. They are implicated in the pathology of various diseases such as atherosclerosis, neurodegenerative diseases, and diabetic complications. The 4-aminomethyl and the 3-hydroxyl substituents of the pyridine ring of PM forms the bidentate structure essential for chelation. $\mathrm{PM}$ forms complexes with $\mathrm{Cu}^{2+}$ and $\mathrm{Fe}^{3+}$ ions and acts as a metal chelator and helps in neutralizing these reactive species. Of the six B6-vitamers, only PM, contains the bis-nucleophilic 3-hydroxy-4aminomethyl-pyridine pharmacophore which can serve as a potent carbonyl scavenger and antiglycation agent. Reactive carbonyl species induce carbonyl stress leading to the accumulation of advanced glycation end products (AGE) that are implicated in Alzheimer's disease, atherosclerosis, diabetes, and aging. Formation of excited states of chromophores and their subsequent interaction with substrate molecules or molecular oxygen is called photosensitization. 3-hydroxypyridine core moiety is possessed by all B6-vitamers and exhibit potent photodynamic activity. B6-vitamers act as photosensitizers and are capable of mediating skin photooxidative damage.

\section{B6 in Disease}

B6 helps in metabolizing the sulphur-containing compounds as well as the methyl-containing molecules. The beneficial effects are appreciable by maintaining the levels of Hcys, which is an important marker and forms the risk factor for cardiovascular diseases (CVD). B6 deficiency is implicated in cognitive decline, Alzheimer's disease, depression, and cancer. Inborn metabolic disorders such as pyridoxinedependent epilepsy and pyridoxamine phosphate oxidase deficiency, cause early-onset of epileptic encephalopathies, malabsorption, cancer, cirrhosis, uremia, and heart failure. Use of alcohol and medications may lead to secondary deficiencies of B6 (Chawla and Kvarnberg, 2014).

A significant inverse correlation is observed between serum PLP and different types of cancers. B6 deficiency leads to the decrease in the enzyme activity of SHMT and BHMT resulting in a shortage of methylene groups for 5,10-methylene-THF production. Thus, misincorporation of uracil instead of thymidine into DNA takes place leading to chromosome strand breaks. Additionally, B6 deficiency gives rise to improper methylation which in turn leads to DNA hypomethylation, a hallmark of tumours. Transsulfuration pathway uses PLP and generates cysteine, an essential component of glutathione. B6 deficiency impairs the detoxification of several carcinogenic compounds by glutathione-Stransferases and glutathione peroxidases. B6 inadequacy may be speculated in hormone-dependent cancer of the breast, uterus, and prostate, and in hypertension (Wu and Lu, 2012).

The potent anti-inflammatory role of B6 is reported in several studies (Frydas et al., 1999; Kiran et al., 2011; Yanaka et al., 2005). In addition to T2D, the beneficial effects of B6 have also been documented in some autoimmune diseases (Marjamaki et al., 2010; Stene et al., 2010). In recent times, the interplay between stem cells and nutrients has prompted interest in the field of developmental biology (Hardikar et al., 2015) and regenerative medicine (DominguesFaria et al., 2016). Treatment with PLP/B6 was not only effective in ameliorating frank diabetes induced with STZ in mice but was also effective in repopulating resident stem cells/progenitors of the pancreas (Kiran et al., 2011) facilitating insulinotropic function. It 
prevents hyperglycaemia-induced superoxide radical formation, lipid peroxidation and suppresses crystallins oxidation in cultured lens cells (Wondrak and Jacobson, 2012). PLP mitigated the secondary complications of diabetes including diabetic nephropathy (Nakamura et al., 2007).

Suboptimal B6 status is associated with agerelated diseases like impaired cognitive functions (Budge et al., 2000; Chandra, 2001; Lehmann et al., 1999) and Alzheimer's disease (Douaud et al., 2013; Malaguarnera et al., 2004). B6 inhibits vascular process by downregulating the differentiation of endothelial progenitor cells (Matsubara et al., 2004). PLP and pyridoxal at higher concentrations were able to suppress the proliferation of endothelial cells isolated from umbilical vein, probably eliciting its effect by inhibition of DNA polymerase and DNA topoisomerase I and II activity. On similar lines, PLP supplementation to the cultures obtained from rat aortic ring demonstrated strong anti-angiogenesis and anti-tumourigenesis effects (Matsubara et al., 2003; Matsubara et al., 2004). Evidence to inhibit cell proliferation, and reduce the stress milieu of the cancerous cells advocates its application as a feasible option in the management of colon cancer (Komatsu et al., 2003). The possible therapeutic role of $\mathrm{B} 6$ in the treatment of patients affected by both autoimmunity and HIV for whom routine immune suppressive are contraindicated needs to be investigated.

\section{Folate}

The water-soluble vitamin B9 (Fig. 3) is also called folate (naturally occurring) or folic acid (FA) (synthetic form). In 1931, Lucy Wills's while working in India, mentioned about an unknown factor which cured pernicious anaemia. Later in 1941, Mitchell et al. described 'folic acid', extracted from spinach

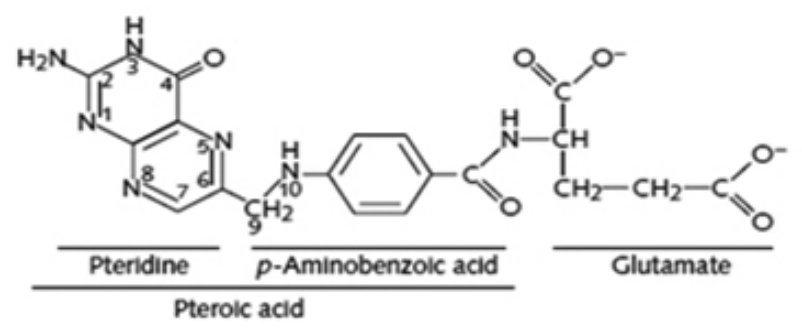

Fig. 3: Structure of folic acid (Adopted from (Shane, 2008) with permission from the authors)
(Bailey et al., 2015). Folate plays a pivotal role in normal growth, development and optimal health. FA becomes biologically active only after its conversion into 5-methyl-tetrahydro folate (THF). Natural folates are composed of a mixture of reduced un-substituted polyglutamyl THFs which exist in different oxidation states (methyl, methylene, formyl, formimino, methenyl). Folate participates in the one-carbon metabolism that takes place in the cytosol, mitochondria, and nucleus and carries out the following functions: synthesis of DNA and RNA precursors (thymidylate and purines), methylation reactions, and metabolism of some amino acids.

\section{Dietary Sources, Requirement, and Deficiency}

Although folate is present in a wide range of animal and plant foods, it is found in relatively low density. Green leafy vegetables (spinach), asparagus, citrus fruits, pulses, legumes, different types of beans, organ meats, liver, and egg yolk, are good sources of dietary folate. The physiological demand of folate is higher in pregnancy and lactation and by select population groups. Because of its low bioavailability, fortification of foods or selected supplementation of $\mathrm{B}_{6}$ to women of child-bearing years may be a better option to overcome this problem. Dietary requirements of folate are mentioned in Table 1.

Dietary insufficiency can be primarily attributed to folate insufficiency. Other factors such as chronic and heavy alcohol consumption and smoking can further exacerbate the condition. Inflammatory bowel diseases (Crohn's disease and ulcerative colitis), celiac disease, tropical sprue can lead to impaired folate absorption. Usage of drugs such as anticonvulsants, diuretics, sulfasalazine and metformin may result in folate deficiency. Genetic factors such as polymorphism in the genes encoding pteroylglutamate hydrolase enzyme (reduces its activity) or methylenetetrahydrofolate reductase (MTHFR) activity also affect folate concentration. Folate insufficiency in the blood is detected by a decrease in plasma folate followed by an increase in plasma Hcys concentration and a reduction in $\mathrm{RBC}$ folate.

\section{Absorption and Transport}

Dietary folates preponderantly exist as reduced polyglutamates. They are hydrolysed by the brush bordered pteroyl polyglutamate hydrolase to 5-methyl- 
THF monoglutamate, followed by their transport to the jejunum of the small intestine for absorption. 5methyl-THF monoglutamate enters the human circulation and gets metabolized to polyglutamate forms by the addition of 4-8 glutamate residues by the enzyme folylpolyglutamate synthetase. 5-methylTHF polyglutamate has to be metabolized to THF via the methionine synthase (MS) reaction or else it might be subjected to tissue retention. FA, as oxidized monoglutamate, undergoes two reductions by dihydrofolate reductase (DHFR) to THF to enter the folate cycle (Smith et al., 2008). The movement of folate and its coenzymes requires transporters-reduced folate carrier (RFC), the proton-coupled folate transporter (PCFT), and the folate receptors (FRs: $\mathrm{FR} \alpha$, and $\mathrm{FR} \beta$ ). RFC has a higher affinity for folate than FA. The FRs aid in the endocytotic reabsorption of folate in the kidney. Removal of polyglutamate chain of dietary folates reduces its bioavailability. It is more labile to heat, hence subjected to considerable loss (50-90\%) during cooking or processing. Dietary folate is retained in the body for some days or weeks. In FA, the pteridine is resistant to chemical oxidation, rendering it stable for several months or few years. Bioavailability of folate is $\approx 100 \%$ when taken as FA supplement on an empty stomach; $85 \%$ for FA fortified foods and $50 \%$ from food (Allen, 2008).

\section{Molecular Functions of Folate}

\section{Serine-glycine Interconversion}

In the one-carbon cycle (Fig. 2), polyglutamyl form of THF (dietary folate) is the key player. Serine in the presence of SHMT using PLP as a cofactor donates its $\beta$-carbon to THF to generate glycine and 5,10-methylene-THF. Mitochondrion supplies the major share of one-carbon units required for cytosolic one-carbon metabolism in the form of formate. A portion of the 5,10-methylene-THF in the presence of MTHFR reduces to 5-methyl-THF. MS uses vitamin B12 (B12) as a cofactor for the conversion of 5-methyl-THF to THF, transferring the methyl group to Hcys, to regenerate methionine. In the nucleus, THF is thought to be involved in histone demethylation along with thymidylate synthesis. (Shane, 2008).

\section{Synthesis of Nucleotides}

5,10-methylene-THF converts to DHF by donating a
$\mathrm{CH}_{2}$ unit to the deoxythymidine monophosphate (dTMP) to generate deoxyuridine monophosphate which is essential for the biosynthesis of DNA. DHF is reduced back to THF by DHFR, which enters the one-carbon cycle again. Likewise, 10-formyl-THF generated from 5,10-methylene-THF is used in the de novo cytosolic purine biosynthesis.

\section{Synthesis of S-adenosylmethionine}

Hcys is methylated to yield methionine which is metabolized to S-adenosylmethionine (SAM) (Fig. 2). SAM acts as a methyl donor for several bioactive molecules, including the methylation of chromatin, RNA, histones and other proteins, neurotransmitters, and phospholipids, and the synthesis of creatine. DNA methyltransferases are involved in the methylation of DNA, which is crucial for inhibition of transcription initiation and stabilization of the genome (Lamprecht and Lipkin, 2003). Nuclear transcription, cell signaling, localization of proteins and mRNA translation are dependent on SAM-dependent methylation (Bailey et al., 2015). Inadequate folate levels impair the remethylation of cellular Hcys leading to hyperhomocysteinemia (HHcys). Hence, the plasma total Hcys level is used as a surrogate marker of folate insufficiency.

\section{Folate in Disease}

Folate inadequacy is a global concern. Impaired folate status is implicated in various chronic diseases including megaloblastic anaemia, neural tube defects (NTDs), CVD, cancer and neurological problems. Genetic factors or B12 deficiency can lead to the accumulation of 5-methyl-THF (methyl trap hypothesis). This process depletes other folate forms, inhibits thymidylate biosynthesis, and ultimately results in megaloblastic anaemia. NTDs are congenital malformations which occur between the 20th and 28th day after conception. It is suggested that folate inadequacy during embryogenesis results in impaired nucleotide biosynthesis and cell division. Elevated Hcys, improper methylation together prevent the closure of the neural tube giving rise to NTDs (anencephaly or spina bifida). FA along with B12 aids in the conversion of Hcys to methionine. Inadequate folate leads to the accumulation of Hcys. HHcys is a marker for cardiovascular and, cerebrovascular diseases and hypertension. 
Folate plays a dual role in cancers. It protects against the initiation of cancer but also aids in the growth and progression of pre-neoplasms and subclinical cancers (Smith et al., 2008). Low folate levels are associated with lymphoma, leukaemia, prostate, colorectal and breast cancer. DNA biosynthesis and SAM-dependent methylation are disturbed by folate inadequacy. Further, de novo synthesis of purines and deoxythymidylate is hampered resulting in misincorporation of uracil in place of thymine causing futile cycles of DNA repair, and chromosome breakage.

The conversion of the non-coenzymatic form of folate to coenzymatic THF derivatives, for incorporation into the active folate pool, is catalyzed by DHFR in two steps. Oral doses of FA greater than 260-280 $\mu \mathrm{g}$ tend to saturate metabolic capacity of the liver, leading to the appearance of unmetabolized folate (UMFA) in the circulation. UMFA is believed to decrease the natural killer cell cytotoxicity. High folate levels may reduce the response to antifolate drugs used against malaria, cancer, rheumatoid arthritis, and psoriasis. High folate levels along with low B12 status may be associated with an increased risk of cognitive impairment, anaemia in the elderly, insulin resistance and obesity in the offsprings of pregnant women. UMFA leads to the growth and progression of preneoplastic cells and subclinical cancers (Smith et al., 2008).

\section{Vitamin B12(SHD)}

Almost a decade of arduous research work went into the treatment of pernicious anaemia and the subsequent discovery of 'nature's most beautiful cofactor', vitamin B12 (B12). Minot, Murphy, and Whipple bagged the Nobel Prize in Medicine for isolating and identifying B12 and Hodgkin for mapping the chemical structure of B12 (Fig. 4). R-group, when occupied by methyl or 5-deoxyadenosyl group (yielding enzymatically active cofactors) is utilized by cytosolic MS and mitochondrial methylmalonyl CoA (MMC) respectively. Binding of hydroxyl or cyano group yields hydroxocobalamin and cyanocobalamin (synthetic inactive forms), respectively which need to be metabolised to active forms in humans (Gille and Schmid, 2015). Under physiological conditions, Cobalt exists in three possible oxidation states in B12 derivatives: $\mathrm{Co}(\mathrm{III}), \mathrm{Co}(\mathrm{II})$, and $\mathrm{Co}(\mathrm{I})$ which determine the function of B12 as enzyme cofactors.

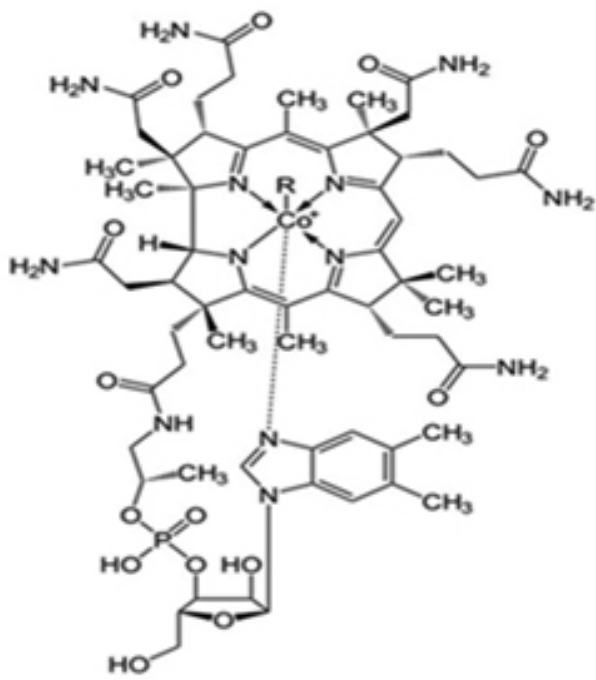

Fig. 4: Structure of vitamin B12. $R=5$ deoxyadenosyl, Me, OH, CN (Source: (Lakshmiah et al., 2016); with permission from the Oxford \& IBH Publishing Co Pvt Ltd)

\section{Dietary Sources, Requirement, and Deficiency}

Humans and other mammals, fungi and plants are incapable of synthesizing B12 unlike prokaryotes (mostly anaerobic). The gastrointestinal environment of the animals (mostly ruminant) favours the growth of B12 synthesising microbial flora. B12 thus produced is absorbed and stored in the tissues like liver, muscles, and milk of the animals which when consumed by humans gain entry into the human food chain (Gille and Schmid, 2015). Spirulina (blue-green algae) and some seaweed are also sources of B12. Dietary requirements of B12 are mentioned in Table 1.

B12 deficiency can be attributed to various factors such as genetic defects (in the genes involved in B12 homeostasis) and low dietary intake of B12 or impairment of absorption. Defects in the gastric mucosa, chronic atrophic gastritis, gastrectomy, malabsorption in the ileum, intestinal stasis, drugs, and intestinal parasites can lead to impaired B12 absorption. Other causes include old age and pernicious anaemia, characterized by autoimmune destruction of gastric parietal cells resulting in a lack of intrinsic factor (IF) which facilitates absorption (Nielsen et al., 2012). B12 deficiency is common because of typically low consumption of animal foods, resulting in inadequate intakes. B12-IF complex absorption in the terminal ileum is calcium dependent which is altered by metformin. Subclinical cobalamin deficiency (SCCD) is epidemiologically more prevalent 
than clinical cobalamin deficiency in the elderly and vegetarian populations. It differs from cobalamin deficiency in many aspects: SCCD is milder yet more widespread. The underlying causes are less severe hence it is less likely to progress. It lacks clinical manifestations so it is challenging to diagnose and may require more than one biomarker for diagnosis (Carmel, 2012).

Though low serum B12 (less than 203 pg/ml) was considered as an indicator of B12 deficiency, intermediate range $(203-350 \mathrm{pg} / \mathrm{ml})$ needed interpretation to confirm the deficiency. Plasma Hcys and plasma methylmalonic acid (MMA) act as surrogate markers of B12 status. Nevertheless, folate or B6 deficiency can also alleviate plasma Hcys hence elevation of MMA is a better indicator of B12 status than Hcys levels. However, recent studies have shown that Hcys (van Guldener, 2006) and MMA (Lindgren, 2002) (Zsengeller et al., 2014) may be elevated in renal insufficiency, so the elevation itself is not always diagnostic. Transcobalamin (TC)-B12 complex represents an efficient, indirect tool for evaluation of intestinal B12 absorption (discussed later) in patients with suspected B12 malabsorption. TCB12 complex helps in assessing the degree of B12 depletion while MMA acts as an indicator of the extent of the deficiency. Hence, more than one diagnostic technique should be used to assess the B12 status (Pawlak et al., 2013).

\section{Absorption and Transportation}

Dietary B12 is bound to protein. The $\mathrm{HCl}$ produced by the stomach severs the protein from B12 resulting in free B12, which then binds to R-binders (or haptocorrins), that protect $\mathrm{B} 12$ from the acidic degradation in the stomach. IF secreted by the parietal cells of stomach binds B12 after degradation of Rbinder by the pancreatic protease near the duodenum. The IF-B12 complex is endocytosed in the terminal ileum. This process is mediated by the cubam receptor complex (cubilin and amnion-less) present on the luminal site of enterocytes. In the enterocyte, after internalization of IF-B12-cubam complex by lysosome, IF is subjected to lysosomal degradation by proteases and cubam is recycled. After dissociating from IF and cubam, free B12 can either serve as a coenzyme by remaining in the enterocyte or can enter the bloodstream (Obeid et al., 2015). B12 exits the enterocyte via a transmembrane protein, multidrug resistance protein-1. B12 entering the circulation is either bound to TC (functionally active) or haptocorrin. The endocytic receptor transmembrane CD320 present on the cell surface of tissues is responsible for the uptake of the TC-B12 complex by the cells. After gaining entry into the cell via CD320 receptor, the TC-B12 complex undergoes dissociation and TC is released into the cytosol. Now B12 undergoes intracellular processing (Nielsen et al., 2012). Excess of B12 in circulation is subjected to renal filtration. Megalin protein of proximal tubule cells is involved in renal filtration and reuptake of TC-B12, preventing the urinary loss of B12 present in the renal glomerular filtrate by internalizing the vitamin complexed with TC. Kidney also acts as a storage organ of B12 next to liver.

\section{Molecular Functions}

B12-dependent enzymes constitute a family that can be divided into three subfamilies: (1) 5 deoxyadenosylcobalamin (AdoCbl) dependent isomerases, (2) methylcobalamin ( $\mathrm{MeCbl}$ ) dependent methyltransferases, and (3) B12-dependent reductive dehalogenases (Banerjee and Ragsdale, 2003).

\section{MeCbl-dependent Methyltransferases}

Hcys remethylation is carried out by MS in the presence of folate wherein B12 acts as a cofactor. 5methyl-THF donates its methyl group to B12 and gets converted to THF. Cobalamin accepts the methyl group and forms methylcobalamin which transfers the methyl group to Hcys to generate methionine. Subsequently, methionine gets converted to SAM, which is involved in several methylation reactions (Fig. 2). Inadequate $B 12$ leads to the defective production of SAM and hence to improper methylation of DNA, RNA, histones and other bioactive molecules. Synthesis of carnitine and myelin are also affected, latter leading to impaired neural function.

\section{AdoCbl-dependent Isomerases}

MMC mutase depends on AdoCbl for the reversible isomerisation of L-methylmalonyl CoA to succinyl CoA. Inadequate B12 synthesis affects MMC activity and consequently accumulation of MMA and depletion of succinyl-CoA. Conversion of succinate to fumarate and malate and consequently the electron transport 
chain are disturbed. Gluconeogenesis which requires succinyl-CoA is also impaired (Mahmood, 2014).

\section{B12-dependent Reductive Dehalogenases}

These are the most recently discovered class of B12 enzymes. Studies exploring the reaction mechanism of the dehalogenases are scarce. B12-dependent reductive dehalogenases found in anaerobic microorganisms participate in the detoxification of aromatic and aliphatic chlorinated organics such as chlorinated phenols and chlorinated ethenes (Banerjee and Ragsdale, 2003).

\section{B12 in Disease}

\section{Methylmalonic Aciduria}

Low intake of B12 or impaired AdoCbl synthesis, specifically result in methylmalonic aciduria, which is an autosomal recessive metabolic disorder leading to neurological effects (Andrade et al., 2014). Amassed MMC undergoes enzymatic hydrolysis to MMA and CoA. MMA is involved in renal tubular dysfunction with progression into chronic tubulointerstitial nephritis and end-stage renal disease (Zsengeller et al., 2014).

\section{Hyperhomocysteinemia (HHcys)}

Dysfunction of MTHFR or inadequate levels of B12 can cause HHcys. Elevated Hcys is, therefore, a result of inadequate folate and B12 levels.

\section{Megaloblastic Anaemia}

Inadequate B12 levels lead to trapping of methyl-THF rendering it unavailable for de novo dTMP synthesis resulting in impaired DNA synthesis. Thus, deficiency of folate along with B12 can cause megaloblastic anaemia.

\section{Neuropathy}

B12 deficiency leads to the dysfunction of MS and results in abnormal functioning of the peripheral nervous system which is also called as cobalamin neuropathy. The exact mechanism needs to be elucidated. B12 deficiency is also suspected in the development of NTDs, age-related macular degeneration and increased risk of frailty and dementia in elderly.

\section{Studies Carried Out in India on B6, Folate, and B12 with Emphasis on Prevalence of Deficiency}

\section{Vitamin B6}

While some experimental and clinical studies were reported on the effect of B6 supplementation on various ailments, studies on the prevalence of B6 deficiency were scarce in India. Early studies, carried out at the National Institute of Nutrition (NIN), in Indian women have shown that B6 requirement is increased in women using combination-type oral contraceptives, leading to biochemical evidence of B6 deficiency. High doses of the vitamin are needed to correct the defect (Ahmed et al., 1975). Beneficial effects of B6 supplementation in mitigating the altered glucose metabolism due to combined steroidal contraceptives have been demonstrated in female rats. The mechanism involved was also elucidated (Vijayalakshmi and Bamji, 1987; Vijayalakshmi et al., 1988). A study amongst schoolboys showed that $61 \%$ had pyridoxine deficiency along with the deficiency of other B-vitamins which was associated with angular stomatitis and glossitis (Bamji et al., 1979). Human subjects with lesions of the mouth responded to treatment with either riboflavin or PN (Lakshmi and Bamji, 1974). Skin lesions typical of vitamins B2 and B6 deficiency have been attributed to impaired collagen cross-linking and maturity which in turn weakens the overlying epithelium. The enzyme lysyl oxidase involved in collagen cross-linking needs PLP as cofactor and vitamin B2 coenzyme FMN is a cofactor for pyridoxine phosphate oxidase involved in the generation of PLP from pyridoxine or pyridoxamine (Prasad et al., 1983).

Recently we reported significantly lowered levels of plasma B6 in type 2 diabetes (T2D) patients compared to normal subjects (Satyanarayana et al., 2011). Subclinical pyridoxine deficiency was shown to be associated with improved glucose tolerance (Rao, 1983). While some studies have reported the beneficial impact of B6 on oxalurea and calculogenesis, others have not (Nath et al., 1990; Sharma et al., 1990). Inflammation was found to be enhanced in pyridoxine deficiency in experimental rats (Lakshmi et al., 1991). Plasma total Hcys levels tended to be higher in women with clinical, and biochemical deficiency of B6. Therapy with pyridoxine reduced its level appreciably (Lakshmi and 
Ramalakshmi, 1998). Biochemical deficiency of B6 and its low concentrations in the milk of mothers from a low-income group at different stages of lactation was reported (Bamji et al., 1986). In a hospital-based study, treatment with B6 prevented seizures in about $7 \%$ of children, a case of pyridoxine-dependent seizures (Ramachandrannair and Parameswaran, 2005). Some studies with experimental animals showed that B6 has antioxidant potential under different conditions (Rao, 1983; Ravichandran and Selvam, 1990; Sharma et al., 1990).

\section{Folate and B12}

Although deficiency of these two vitamins can occur primarily as a result of insufficient dietary intake or poor absorption, various other factors such as sociocultural, gender, age, genetic and ethnic backgrounds are likely to influence their occurrence. Deficiency of folate and B12, as assessed by the blood levels, has been reported across population groups and in different stages of development in both developed and developing countries.

A series of experimental studies were carried out at the NIN (India) in support of the hypothesis that the risk of developing metabolic diseases is increased by maternal under-nutrition. These studies reveal that chronic maternal dietary folate and/or B12 restrictions alter body composition and glucose metabolism in rat offsprings. These changes are partially correctable by rehabilitation, suggesting the importance of these vitamins during pregnancy and lactation on growth, muscle development, glucose tolerance and metabolism in the offspring (Kumar et al., 2013; Kumar et al., 2014). B12 deficiency in mothers leads to an alteration in the kidney proteome in rat pups (Ahmad et al., 2015). The severe B12 restriction had a profound impact on the physiology of adult female mice (Ghosh et al., 2016). Some experimental studies indicate that FA and B12 either separately or in combination are effective in reducing oxidative stress and tissues damage due to various insults in animals (Bhattacharjee et al., 2016; Majumdar et al., 2012; Majumdar et al., 2009; Pote et al., 2006; Singh et al., 2011).
In the Indian context, the majority of the studies related to folate and B12 deficiencies are focused on population groups such as the elderly, children, and pregnant women. These are summarized in Table 2. In other cases, they are studied in connection with some disease conditions such as cognitive dysfunction, anaemia, low birth weight, maternal nutrition and HHcys (Agarwal, 2011; Veena et al., 2010) (Table 2). Recently we evaluated the status of folate and B12 in the adult population of different age groups. The overall prevalence of deficiency was $12 \%$ in case of folate, and $35 \%$ in case of B12 deficiency. These results also indicate a higher prevalence of B12 deficiency than folate in apparently healthy adults (Sivaprasad et al., 2016). A similar observation has been made in earlier studies from India (Table 2).

\section{Conclusions and Future Directions}

Among the B-vitamins, B6, folate, and B12 together play crucial and interdependent roles in various biochemical and molecular functions including the network of one-carbon metabolism. Deficiency of these vitamins is implicated in various chronic diseases including megaloblastic anaemia, NTDs, CVD, cancer and neurological problems. Studies on the status of B6, particularly on the prevalence of B6 deficiency and its contribution to disease burden, are scarce in India. Investigations are necessary to establish the prevalence of B6 deficiency across the age-groups in different populations. The majority of the studies on folate and B12 were on the elderly people, children, and pregnant women. Overall there is a relatively higher prevalence of B12 deficiency compared to folate. The role of folate and B12 in disease conditions such as cognitive dysfunction, anaemia, low birth weight, maternal nutrition has also been studied. More studies on the status of these vitamins in apparently healthy populations in relation to diet need to be evaluated, since dietary deficiency of these vitamins is rampant. Based on the evidence generated, sustainable dietary intervention such as consumption of micronutrient-rich foods and also fortification of foods with these vitamins need to be evolved to ensure adequate intake so as to prevent the health complications associated with these vitamins. 
Table 2: Studies carried out in India on folate and B12

\begin{tabular}{ll}
\hline Reference & Target Population \\
\hline (Abraham et al., 2006) & $\begin{array}{l}\text { Cases with acute coronary syndromes } \\
\text { and controls }\end{array}$ \\
(Agrawal et al., 2015) & $\begin{array}{l}\text { Cross-sectional data from India's third } \\
\text { NFHS, 2005-06 }\end{array}$ \\
(Aroda et al., 2016) & $\begin{array}{l}\text { Participants from Diabetes Prevention } \\
\text { Program Outcomes Study }\end{array}$ \\
(Arya et al., 2011) & $\begin{array}{l}\text { Children with epilepsy, 6-15 years } \\
\text { (Balarajan } \text { et al., 2013) }\end{array}$ \\
$\begin{array}{l}\text { Pooled data from 1998/1999 and 2005/ } \\
\text { 2006 National Family Health Surveys } \\
\text { (NHFS) of India }\end{array}$
\end{tabular}

(Bansal et al., 2016) Slum dwelling anaemic adolescent girls

(Bhardwaj et al., 2013) Adolescents with iron deficiency anaemia, 11-19 years

(Bhargava et al., 2012) Patients with vascular disease and controls

(Bhat et al., 2009) Children and parents from 109 families

(Bhatia et al., 2012) Patients with B12 deficiency

(Bhoite and Iyer, 2012) 4-7th standard school children

(Chandelia et al., 2012) Children with nutritional anaemia, 0.5-5 years

(Chandra et al., 2002) Children, 6-132 months

(Chandy et al., 2008) Patients with colorectal cancer and controls

(Dhobale et al., 2012) Preterm mothers, preterm mothers due to preeclampsia and controls

(Duggan et al., 2014) Pregnant women with <14 weeks of gestation

(Dwarkanath et al., 2013) Pregnant women

(Gulvady et al., 2007) Senior executives of a company

(Iyengar and Rajalakshmi, Expectant mothers 1975)

(Iyengar, 1971) Pregnant women

(Jain et al., 2015) Childhood acute lymphoblastic leukaemia survivors, $5-18$ years
Outcome

Significant correlation between Hcys, B12 and folate were lacking

Reduction in preeclampsia or eclampsia related symptoms is associated with an adequately diversified dietary intake and iron and IFA supplementation in pregnancy

Metformin usage increased the risk of B12 deficiency

FA supplementation was helpful in decreasing the phenytoin therapy induced gingival overgrowth in children

IFA supplementation during pregnancy was helpful to overcome low birth weights

Anaemia could be effectively cured by IFA supplementation with or without B12

Anaemia with B12 deficiency but not FA deficiency posed to be a major public health issue

Folate fortification on a large scale will be helpful in reducing the rate and morbidity of the vascular disease

B12 absorption in individuals with low B12 status may be assessed by an increase in plasma holo-TC

Mean corpuscular volume (MCV) is not a dependable factor for screening the presumed diagnosis of macrocytic anaemia in these subjects

Weekly IFA along with deworming is helpful in improving the haemoglobin levels of the children

Supplementation of B12 in addition to iron and FA resulted in an improved haematological response

Deficiency of folate and B12 is an etiological factor for megaloblastic anaemia in children

Folate and Hcys levels did not differ significantly, but B12 levels increased in the colorectal cancer cases

Altered maternal micronutrients and resultant increased Hcys concentrations exist in preterm mothers

Oral B12 supplementation of urban Indian women throughout pregnancy and early lactation helps to increase the B12 status of mothers and infants

Unbalanced B12 and folate intakes or status during pregnancy lead to adverse birth outcomes

Substantial improvements in serum B12 and vitamin D3 values were observed as a result of oral therapy, sun exposure, and dietary modifications

IFA (iron FA) supplementation to pregnant women on large scale brings about an improvement in the incidence of pregnancy anaemia and also a reduction in the infant morbidity and mortality rate due to low birth weight babies

Recommends $500 \mu \mathrm{g}$ of FA supplementation to all pregnant women during the last 100 days of pregnancy

Prevalence of deficiencies of folate and B12 was not significantly different in subjects with or without neuropathy 
(Jani et al., 2015)

(Jathar et al., 1970)

(Jeeja et al., 2014)

(Kanani and Poojara, 2000)

(Kapil and Bhadoria, 2014)

(Karanth et al., 2015)

(Katre et al., 2010)

(Khanduri et al., 2005)

(Krishnaveni et al., 2014) Pregnant women at $30 \pm 2$ weeks of gestation

(Kumar and Rajagopalan, School children, age 7-11 years 2007)

(Kvestad et al., 2015) Children, 6-30 months

(Mahajan and Aundhakar, Patients attending a tertiary care center 2015)

(Malhotra et al., 2014) Data from the NHFS, 2005-06

(Manger et al., 2011) Children, age 6-30 months

(Menon et al., 2011) Non-pregnant rural and tribal women, 18-30 years

(Misra et al., 2002) Urban slum dwellers and adjacent nonslum dwellers

(Misra et al., 2016)

(Nayyar et al., 2014)

(Osei et al., 2010)

(Pasricha et al., 2011)

(Pathak et al., 2007)

Pregnant women

(Premkumar et al., 2012) Patients with pancytopenia
Development of culturally sensitive strategies for improvement of folate insufficiency is highlighted

The mean serum B12 value in non-vegetarian mothers was higher as compared to lactovegetarians

FA may be helpful to reduce the total Hcy level and thus reduce cardiovascular disease (CVD) risk in children on anti-epileptic drug treatment

IFA supplementation is beneficial for adolescents who are underweight

Nutritional anaemia in adolescents can be addressed with IFA and B12 supplementation

Karanth's test is useful for screening B12 deficiency and requires further evaluation in a larger study population

Increasing dose of B12 but not FA seemed to lower the plasma total Hcys levels

Established normal levels for serum B12 and B9: 47\% had subnormal levels of serum B12 or B9, B12 deficiency being five times more common than B9

Maternal B12 was not related to offspring outcomes whereas maternal Hcys and folate positively associated with glucose concentration and higher HOMA-IR respectively

The multiple micronutrient fortified salt helped to improve the multiple micronutrient status and cognition in children

Supplementation of B12 and FA is beneficial in improving gross motor and problem-solving skills

The study reported the prevalence of B12 and FA in patients attending a tertiary care center with symptoms related to several systems including haematology, dermatology, gastrointestinal, neurology, and neuropsychiatry

Foods rich in micronutrients along with IFA supplementation during pregnancy helped to increase the birth weight

Poor folate status was independently associated with persistent diarrhoea

Zinc, B12, and iron are primarily deficient in these women

Low intakes of FA and B12 and HHcys were observed in both the groups

B12 deficiency was connected with the reduction in glutathione and total antioxidant capacity and increase in malondialdehyde levels

Increased severity and early onset of phenytoin-induced gingival enlargement were associated with low serum FA levels

Deficiency of micronutrients and growth impairment are widespread among school children

Breastfed children between 1-2 years of age should be especially targeted during micronutrient supplementation programs

Apart from iron and FA, B12 deficiency may play a major role in causing anaemia

B12 deficiency was common and was widely underdiagnosed most of the times 
(Ragasudha et al., 2012) Women with invasive cervical cancer and healthy women

(Refsum et al., 2001)

(Samuel et al., 2013)

(Satyanarayana et al., 2011)

(Sen and Kanani, 2009)

(Sen et al., 2008)

(Shobha et al., 2011)

(Sivaprasad et al., 2016)

(Strand et al., 2013)

(Strand et al., 2015)

(Sukla and Raman, 2012)

(Tandon et al., 2015)

(Taneja et al., 2007)

(Taneja et al., 2013)

(Thomas et al., 2015)

(Veena et al., 2010)

(Vir et al., 2008)

(Wendt et al., 2015)

(Yaikhomba et al., 2015)

(Yajnik et al., 2006)

(Yajnik et al., 2007)

(Yajnik et al., 2008)
Patients with CVD, diabetes and healthy controls, 27-55 years

Pregnant women with $\leq 14$ weeks of gestation

Diabetic patients with and without retinopathy and controls

School girls, 9-13 years

Cataract patients and controls

Healthy elderly urban subjects

Apparently healthy population, 20-85 years

Children, 12-18 months

Children, 6-35 months

Healthy population from four Eastern states of India

New-borns

Children with acute lymphoblastic leukaemia

Pre-school children, 6-30 months

Children, 6-30 months

Adolescents with anaemia, 10-18 years

Children, 9-10 years

Adolescent school girls and nonschoolgirls

District Level Household Survey (2007-08) data

Children with severe acute malnutrition

Rural, slum and middle-class urban residents, 39 years

Non-pregnant vegetarian women, 20-50 years

Pregnant women, 18 and 28 weeks of gestation
A synergistic role of folate and B12 was observed in invasive cervical cancer

Metabolic signs of B12 deficiency were observed which could be because of the vegetarian diet

Primiparity and low consumption of yoghurt and fish were related to a high prevalence of $\mathrm{B} 12$ deficiency in early pregnancy

B12 deficiency could be an independent risk factor for diabetic retinopathy

Effect of daily and intermittent IFA supplementation is comparable regarding beneficial effects on cognition

High Hcys and low folate and B12 in cataract patients might be the cause of cataract pathogenesis

Higher B12 intake was observed in the elderly population

The overall prevalence of FA deficiency was $12 \%$, and the B12 deficiency was $35 \%$ in the adult population

B12 and folate are strongly associated with a cognitive performance which demands supplementation trials for these vitamins

B12 deficiency is directly related to poor growth

High frequency of HHcys and B12 deficiency in the apparently healthy population can be the underlying reason for the susceptibility of individuals with MTHFR C677T to various disorders

B12, folate, HHcys and MTHFR 677T are risk factors for low birth weight

Baseline undernutrition of B12 and FA has an adverse influence on the outcome and occurrence of complications during induction chemotherapy in these children

Low B12 and FA concentrations were associated with elevated total Hcys and MMA concentrations

FA or B12 supplementation was not helpful to reduce common childhood infections

Anaemic adolescents are more prone to folate and B12 deficiencies than iron deficiency

Better cognitive function in children was associated with higher maternal folate, rather than B12 concentrations during pregnancy

Weekly IFA supplementation combined with monthly education sessions and deworming every 6 months is cost-effective in lowering the prevalence of anaemia in adolescent girls

Individual and antenatal care factors are crucial for IFA receipt and consumption

B12 deficiency was more common than IFA deficiencies

Vegetarians and middle-class urban dwellers commonly have low B12 and high Hcys levels

High prevalence of low B12 status and high plasma total Hcy concentrations is common in Indian women

The epidemic of adiposity and T2D may be contributed by low maternal B12 and high FA

A Pubmed search was performed to retrieve the studies related to the status of folate and B12 in the Indian population 


\section{References}

Abraham R, John M J, Calton R and Dhanoa J (2006) Raised serum homocysteine levels in patients of coronary artery disease and the effect of vitamin B12 and folate on its concentration Indian journal of clinical biochemistry: IJCB 21 95-100

Agarwal R (2011) Vitamin B(1)(2) deficiency \& cognitive impairment in elderly population The Indian journal of medical research 134 410-412

Agrawal S, Fledderjohann J, Vellakkal S and Stuckler D (2015) Adequately diversified dietary intake and iron and folic acid supplementation during pregnancy is associated with reduced occurrence of symptoms suggestive of preeclampsia or eclampsia in Indian women PloS one $\mathbf{1 0}$ e0119120

Ahmad S, Basak T, Anand Kumar K, Bhardwaj G, Lalitha A, Yadav D K, Chandak G R, Raghunath M and Sengupta S (2015) Maternal micronutrient deficiency leads to alteration in the kidney proteome in rat pups Journal of proteomics 127 178-184

Ahmed F, Bamji M S and Iyengar L (1975) Effect of oral contraceptive agents on vitamin nutrition status The American journal of clinical nutrition 28 606-615

Allen L H (2008) Causes of vitamin B12 and folate deficiency Food and nutrition bulletin 29 S20-34; discussion S35-27

Andrade V M, Dal Pont, H S Leffa, D D Damiani A P, Scaini G, Hainzenreder G, Streck E L, Ferreira G C and Schuck P F (2014) Methylmalonic acid administration induces DNA damage in rat brain and kidney Molecular and cellular biochemistry 391 137-145

Aroda V R, Edelstein S L, Goldberg R B, Knowler W C, Marcovina S M, Orchard T J, Bray G A, Schade D S, Temprosa M G, White N H et al. (2016) Long-term Metformin Use and Vitamin B12 Deficiency in the Diabetes Prevention Program Outcomes Study The Journal of clinical endocrinology and metabolism 101 1754-1761

Arya R, Gulati S, Kabra M, Sahu J K and Kalra V (2011) Folic acid supplementation prevents phenytoin-induced gingival overgrowth in children Neurology 76 1338-1343

Bailey L B, Stover P J, McNulty H, Fenech M F, Gregory J F 3rd, Mills J L, Pfeiffer C M, Fazili Z, Zhang M, Ueland P $\mathrm{M}$ et al (2015) Biomarkers of Nutrition for DevelopmentFolate Review The Journal of nutrition 145 1636S-1680S

Balarajan Y, Subramanian S V and Fawzi W W (2013) Maternal iron and folic acid supplementation is associated with lower risk of low birth weight in India The Journal of nutrition 143 1309-1315
Bamji M S, Prema K, Jacob C M, Ramalakshmi B A and Madhavapeddi R (1986) Relationship between maternal vitamins B2 and B6 status and the levels of these vitamins in milk at different stages of lactation A study in a lowincome group of Indian women Human nutrition Clinical nutrition 40 119-124

Bamji M S, Sarma K V and Radhaiah G (1979) Relationship between biochemical and clinical indices of B-vitamin deficiency A study in rural school boys The British journal of nutrition 41 431-441

Banerjee R and Ragsdale S W (2003) The many faces of vitamin B12: catalysis by cobalamin-dependent enzymes Annual review of biochemistry 72 209-247

Bansal P G, Toteja G S, Bhatia N, Vikram N K and Siddhu A (2016) Impact of weekly iron folic acid supplementation with and without vitamin B12 on anaemic adolescent girls: A randomised clinical trial European journal of clinical nutrition 70 730-737

Bhardwaj A, Kumar D, Raina S K, Bansal P, Bhushan S and Chander V (2013) Rapid Assessment for Coexistence of Vitamin B12 and Iron Deficiency Anemia among Adolescent Males and Females in Northern Himalayan State of India Anemia 2013959605

Bhargava S, Ali A, Bhargava E K, Manocha A, Kankra M, Das S and Mohan Srivastava L (2012) Lowering homocysteine and modifying nutritional status with folic acid and vitamin $\mathrm{B}(12)$ in Indian patients of vascular disease Journal of clinical biochemistry and nutrition $\mathbf{5 0} 222-226$

Bhat D S, Thuse N V, Lubree H G, Joglekar C V, Naik S S, Ramdas L V, Johnston C, Refsum H, Fall C H and Yajnik C S (2009) Increases in plasma holotranscobalamin can be used to assess vitamin B-12 absorption in individuals with low plasma vitamin B-12 The Journal of nutrition 1392119 2123

Bhatia P, Kulkarni J D and Pai S A (2012) Vitamin B12 deficiency in India: mean corpuscular volume is an unreliable screening parameter The National medical journal of India 25 336338

Bhattacharjee A, Prasad S K, Pal S, Maji B, Syamal A K and Mukherjee S (2016) Synergistic protective effect of folic acid and vitamin B12 against nicotine-induced oxidative stress and apoptosis in pancreatic islets of the rat Pharmaceutical biology 54 433-444

Bhoite R M and Iyer U M (2012) Effect of deworming vs IronFolic acid supplementation plus deworming on growth, hemoglobin level, and physical work capacity of schoolchildren Indian pediatrics 49 659-661 
Budge M, Johnston C, Hogervorst E, de Jager C, Milwain E, Iversen S D, Barnetson L, King E and Smith A D (2000) Plasma total homocysteine and cognitive performance in a volunteer elderly population Annals of the New York Academy of Sciences $\mathbf{9 0 3}$ 407-410

Carmel R (2012) Subclinical cobalamin deficiency Current opinion in gastroenterology 28 151-158

Chandelia S, Chandra J, Narayan S, Aneja S, Chawla H M, Sharma S and Mrig S (2012) Addition of cobalamin to iron and folic acid improves hemoglobin rise in nutritional anemia Indian journal of pediatrics 79 1592-1596

Chandra J, Jain V, Narayan S, Sharma S, Singh V, Kapoor A K and Batra S (2002) Folate and cobalamin deficiency in megaloblastic anemia in children Indian pediatrics 39453 457

Chandra R K (2001) Effect of vitamin and trace-element supplementation on cognitive function in elderly subjects Nutrition 17 709-712

Chandy S, Sadananda Adiga M N, Ramaswamy G, Ramachandra C and Krishnamoorthy L (2008) Effect of Vitamin B(12) and Folate on Homocysteine levels in colorectal cancer Indian journal of clinical biochemistry : IJCB $23258-261$

Chawla J and Kvarnberg D (2014) Hydrosoluble vitamins Handbook of clinical neurology 120 891-914

Clase C M, Ki V and Holden R M (2013) Water-soluble vitamins in people with low glomerular filtration rate or on dialysis: A review Seminars in dialysis 26 546-567

Dhobale M, Chavan P, Kulkarni A, Mehendale S, Pisal H and Joshi S (2012) Reduced folate, increased vitamin B(12) and homocysteine concentrations in women delivering preterm Annals of nutrition \& metabolism 61 7-14

Domingues-Faria C, Vasson M P, Goncalves-Mendes N, Boirie $\mathrm{Y}$ and Walrand $\mathrm{S}$ (2016) Skeletal muscle regeneration and impact of aging and nutrition Ageing research reviews $\mathbf{2 6}$ 22-36

Douaud G, Refsum H, de Jager C A, Jacoby R, Nichols T E, Smith S M and Smith A D (2013) Preventing Alzheimer's disease-related gray matter atrophy by B-vitamin treatment Proceedings of the National Academy of Sciences of the United States of America 110 9523-9528

Duggan C, Srinivasan K, Thomas T, Samuel T, Rajendran R, Muthayya S, Finkelstein J L, Lukose A, Fawzi W, Allen L $\mathrm{H}$ et al (2014) Vitamin B-12 supplementation during pregnancy and early lactation increases maternal, breast milk, and infant measures of vitamin B-12 status The Journal of nutrition 144 758-764

Dwarkanath P, Barzilay J R, Thomas T, Thomas A, Bhat S and Kurpad A V (2013) High folate and low vitamin B-12 intakes during pregnancy are associated with small-forgestational age infants in South Indian women: a prospective observational cohort study The American journal of clinical nutrition 98 1450-1458

Frydas S, Papaioanou N, Vlemmas I, Theodoridis I, Anogiannakis G, Vacalis D, Trakatellis A, Barbacane R C, Reale M and Conti P (1999) Vitamin B6-deficient diet plus 4deoxypyridoxine (4-DPD) reduces the inflammatory response induced by $\mathrm{T}$ spiralis in diaphragm, masseter and heart muscle tissue of mice Molecular and cellular biochemistry 197 79-85

Ghosh S, Sinha J K, Putcha U K and Raghunath M (2016) Severe but Not Moderate Vitamin B12 Deficiency Impairs Lipid Profile, Induces Adiposity, and Leads to Adverse Gestational Outcome in Female C57BL/6 Mice Frontiers in nutrition 31

Gille D and Schmid A (2015) Vitamin B12 in meat and dairy products Nutrition reviews 73 106-115

Gulvady C, Pingle S and Shanbhag S (2007) Incidence of vitamin B12 / D3 deficiency among company executives Indian journal of occupational and environmental medicine 11 83-85

Hardikar AA, Satoor S N, Karandikar M S, Joglekar M V, Puranik A S, Wong W, Kumar S, Limaye A, Bhat D S, Januszewski A S et al. (2015) Multigenerational Undernutrition Increases Susceptibility to Obesity and Diabetes that Is Not Reversed after Dietary Recuperation Cell metabolism 22 312-319

ICMR (2010) Nutrient requirements and recommended dietary allowances for Indians A Report of the Expert Group of Indian Council of Medical Research New Delhi

Iyengar L (1971) Folic acid requirements of Indian pregnant women American journal of obstetrics and gynecology 111 13-16

Iyengar L and Rajalakshmi K (1975) Effect of folic acid supplement on birth weights of infants American journal of obstetrics and gynecology 122 332-336

Jain P, Gulati S, Toteja G S, Bakhshi S, Seth R and Pandey R M (2015) Serum alpha tocopherol, vitamin B12, and folate levels in childhood acute lymphoblastic leukemia survivors with and without neuropathy Journal of child neurology 30 786-788

Jani R, Salian N, Udipi S, Ghugre P, Lohia N, Haas J and Boy E (2015) Folate status and intake of tribal Indian adolescents aged 10 to 17 years Food and nutrition bulletin 36 14-23

Jathar V S, Kamath S A, Parikh M N, Rege D V and Satoskar R S (1970) Maternal milk and serum vitamin B12, folic acid, and protein levels in Indian subjects Archives of disease in 
childhood 45 236-241

Jeeja M C, Jayakrishnan T, Narayanan P V, Kumar M S, Thejus T and Anilakumari V P (2014) Folic acid supplementation on homocysteine levels in children taking antiepileptic drugs: A randomized controlled trial Journal of pharmacology \& pharmacotherapeutics 5 93-99

Kanani S J and Poojara R H (2000) Supplementation with iron and folic acid enhances growth in adolescent Indian girls The Journal of nutrition 130 452S-455S

Kapil U and Bhadoria A S (2014) Prevalence of Folate, Ferritin and Cobalamin Deficiencies amongst Adolescent in India Journal of family medicine and primary care 3 247-249

Karanth V K, Karanth L, Karanth T K, Karanth S K and Bekur R (2015) A novel screening tool (Karanth's test) for vitamin B12 deficiency: A pilot study BMC research notes $\mathbf{8} 778$

Katre P, Bhat D, Lubree H, Otiv S, Joshi S, Joglekar C, Rush E and Yajnik C (2010) Vitamin B12 and folic acid supplementation and plasma total homocysteine concentrations in pregnant Indian women with low B12 and high folate status Asia Pacific journal of clinical nutrition 19 335-343

Khanduri U, Sharma A and Joshi A (2005) Occult cobalamin and folate deficiency in Indians The National medical journal of India 18 182-183

Kiran S G, Dorisetty R K, Umrani M R, Boindala S, Bhonde R R, Chalsani M, Singh H and Venkatesan V (2011) Pyridoxal 5 ' phosphate protects islets against streptozotocin-induced beta-cell dysfunction - in vitro and in vivo Experimental biology and medicine 236 456-465

Komatsu S, Yanaka N, Matsubara K and Kato N (2003) Antitumor effect of vitamin B6 and its mechanisms Biochimica et biophysica acta 1647 127-130

Krishnaveni G V, Veena S R, Karat S C, Yajnik C S and Fall C H (2014) Association between maternal folate concentrations during pregnancy and insulin resistance in Indian children Diabetologia 57 110-121

Kumar K A, Lalitha A, Pavithra D, Padmavathi I J, Ganeshan M, Rao K R, Venu L, Balakrishna N, Shanker N H, Reddy S U et al. (2013) Maternal dietary folate and/or vitamin B12 restrictions alter body composition (adiposity) and lipid metabolism in Wistar rat offspring The Journal of nutritional biochemistry 24 25-31

Kumar K A, Lalitha A, Reddy U, Chandak G R, Sengupta S and Raghunath M (2014) Chronic maternal vitamin B12 restriction induced changes in body composition \& glucose metabolism in the Wistar rat offspring are partly correctable by rehabilitation PloS one $\mathbf{9}$ e112991
Kumar M V and Rajagopalan S (2007) Multiple micronutrient fortification of salt and its effect on cognition in Chennai school children Asia Pacific journal of clinical nutrition 16 505-511

Kvestad I, Taneja S, Kumar T, Hysing M, Refsum H, Yajnik C S, Bhandari N, Strand T A, Folate and Vitamin B S G (2015) Vitamin B12 and Folic Acid Improve Gross Motor and Problem-Solving Skills in Young North Indian Children: A Randomized Placebo-Controlled Trial PloS one 10 e0129915

Lakshmi A V and Bamji M S (1974) Tissue pyridoxal phosphate concentration and pyridoxaminephosphate oxidase activity in riboflavin deficiency in rats and man The British journal of nutrition 32 249-255

Lakshmi A V and Ramalakshmi B A (1998) Effect of pyridoxine or riboflavin supplementation on plasma homocysteine levels in women with oral lesions The National medical journal of India 11 171-172

Lakshmi R, Lakshmi A V, Divan PV and Bamji M S (1991) Effect of riboflavin or pyridoxine deficiency on inflammatory response Indian journal of biochemistry \& biophysics $\mathbf{2 8}$ 481-484

Lakshmiah N, Lakshmi A V and Reddy G B (2016) Water soluble vitamins In: Text Book of Human Nutrition (MS Bamji, K Krishnaswamy, GNV Brahmam eds) 4th ed, Oxford \& IBH Publishing Co Pvt Ltd New Delhi

Lamprecht S A and Lipkin M (2003) Chemoprevention of colon cancer by calcium, vitamin D and folate: molecular mechanisms Nature reviews Cancer 3 601-614

Lehmann M, Gottfries C G and Regland B (1999) Identification of cognitive impairment in the elderly: homocysteine is an early marker Dementia and geriatric cognitive disorders $1012-20$

Lindgren A (2002) Elevated serum methylmalonic acid How much comes from cobalamin deficiency and how much comes from the kidneys? Scandinavian journal of clinical and laboratory investigation 62 15-19

Mackey A, Davis S and Gregory J (2005) Vitamin B6 In: Modern Nutrition in Health and Disease (Shils M, Shike M, Ross A, Caballero B, Cousins R, eds) 10th ed, Baltimore, MD: Lippincott Williams \& Wilkins

Mahajan S K and Aundhakar S C (2015) A study of the prevalence of serum vitamin B12 and folic Acid deficiency in Western maharashtra Journal of family medicine and primary care 4 64-68

Mahmood L (2014) The metabolic processes of folic acid and Vitamin B12 deficiency Journal of Health Research and Reviews $15-9$ 
Majumdar S, Maiti A, Karmakar S, Das A S, Mukherjee S, Das D and Mitra C (2012) Antiapoptotic efficacy of folic acid and vitamin $\mathrm{B}(1)(2)$ against arsenic-induced toxicity Environmental toxicology 27 351-363

Majumdar S, Mukherjee S, Maiti A, Karmakar S, Das A S, Mukherjee M, Nanda A and Mitra C (2009) Folic acid or combination of folic acid and vitamin $\mathrm{B}(12)$ prevents shortterm arsenic trioxide-induced systemic and mitochondrial dysfunction and DNA damage Environmental toxicology 24 377-387

Malaguarnera M, Ferri R, Bella R, Alagona G, Carnemolla A and Pennisi G (2004) Homocysteine, vitamin B12 and folate in vascular dementia and in Alzheimer disease Clinical chemistry and laboratory medicine 42 1032-1035

Malhotra N, Upadhyay R P, Bhilwar M, Choy N and Green T (2014) The role of maternal diet and iron-folic acid supplements in influencing birth weight: evidence from India's National Family Health Survey Journal of tropical pediatrics $60454-460$

Manger M S, Taneja S, Strand T A, Ueland P M, Refsum H, Schneede J, Nygard O, Sommerfelt $\mathrm{H}$ and Bhandari N (2011) Poor folate status predicts persistent diarrhea in 6to 30-month-old north Indian children The Journal of nutrition 141 2226-2232

Marjamaki L, Niinisto S, Kenward M G, Uusitalo L, Uusitalo U, Ovaskainen M L, Kronberg-Kippila C, Simell O, Veijola $\mathrm{R}$, Ilonen J et al. (2010) Maternal intake of vitamin D during pregnancy and risk of advanced beta cell autoimmunity and type 1 diabetes in offspring Diabetologia 53 1599-1607

Matsubara K, Matsumoto H, Mizushina Y, Lee J S and Kato N (2003) Inhibitory effect of pyridoxal 5'-phosphate on endothelial cell proliferation, replicative DNA polymerase and DNA topoisomerase International journal of molecular medicine 12 51-55

Matsubara K, Mori M, Akagi R and Kato N (2004) Antiangiogenic effect of pyridoxal 5'-phosphate, pyridoxal and pyridoxamine on embryoid bodies derived from mouse embryonic stem cells International journal of molecular medicine 14 819-823

McCormick D (2006) Vitamin B6 In: Present Knowledge in Nutrition (Bowman B, Russell R, eds) 9th ed, Washington, DC: International Life Sciences Institute

Menon K C, Skeaff S A, Thomson C D, Gray A R, Ferguson E L, Zodpey S, Saraf A, Das P K, Toteja G S and Pandav C S (2011) Concurrent micronutrient deficiencies are prevalent in nonpregnant rural and tribal women from central India Nutrition 27 496-502
Misra A, Vikram N K, Pandey R M, Dwivedi M, Ahmad F U, Luthra K, Jain K, Khanna N, Devi J R, Sharma R et al. (2002) Hyperhomocysteinemia, and low intakes of folic acid and vitamin B12 in urban North India European journal of nutrition $\mathbf{4 1}$ 68-77

Misra U K, Kalita J, Singh S K and Rahi S K (2016) Oxidative Stress Markers in Vitamin B12 Deficiency Molecular neurobiology

Nakamura S, Li H, Adijiang A, Pischetsrieder M and Niwa T (2007) Pyridoxal phosphate prevents progression of diabetic nephropathy Nephrology, dialysis, transplantation : Official publication of the European Dialysis and Transplant Association - European Renal Association 22 2165-2174

Nath R, Thind S K, Murthy M S, Farooqui S, Gupta R and Koul H K (1990) Role of pyridoxine in oxalate metabolism Annals of the New York Academy of Sciences 585 274-284

Nayyar A S, Khan M, Vijayalakshmi K R, Suman B, Subhas G T, Nataraju B and Anitha M (2014) Phenytoin, folic acid and gingival enlargement: Breaking myths Contemporary clinical dentistry 5 59-66

Nielsen M J, Rasmussen M R, Andersen C B, Nexo E and Moestrup S K (2012) Vitamin B12 transport from food to the body's cells-a sophisticated, multistep pathway Nature reviews Gastroenterology \& hepatology 9 345354

Obeid R, Fedosov S N and Nexo E (2015) Cobalamin coenzyme forms are not likely to be superior to cyano- and hydroxylcobalamin in prevention or treatment of cobalamin deficiency Molecular nutrition \& food research 59 13641372

Osei A, Houser R, Bulusu S, Joshi T and Hamer D (2010) Nutritional status of primary schoolchildren in Garhwali Himalayan villages of India Food and nutrition bulletin 31 221-233

Pasricha S R, Shet A S, Black J F, Sudarshan H, Prashanth N S and Biggs B A (2011) Vitamin B-12, folate, iron, and vitamin A concentrations in rural Indian children are associated with continued breastfeeding, complementary diet, and maternal nutrition The American journal of clinical nutrition 94 1358-1370

Pathak P, Kapil U, Yajnik C S, Kapoor S K, Dwivedi S N and Singh R (2007) Iron, folate, and vitamin B12 stores among pregnant women in a rural area of Haryana State, India Food and nutrition bulletin 28 435-438

Pawlak R, Parrott S J, Raj S, Cullum-Dugan D and Lucus D (2013) How prevalent is vitamin B(12) deficiency among vegetarians? Nutrition reviews 71 110-117 
Pote M S, Gandhi N M and Mishra K P (2006) Antiatherogenic and radioprotective role of folic acid in whole body gammairradiated mice Molecular and cellular biochemistry 292 $19-25$

Prasad R, Lakshmi A V and Bamji M S (1983) Impaired collagen maturity in vitamins B2 and B6 deficiency-probable molecular basis of skin lesions Biochemical medicine $\mathbf{3 0}$ 333-341

Premkumar M, Gupta N, Singh T and Velpandian T (2012) Cobalamin and folic acid status in relation to the etiopathogenesis of pancytopenia in adults at a tertiary care centre in north India Anemia 2012707402

Ragasudha P N, Thulaseedharan J V, Wesley R, Jayaprakash P G, Lalitha P and Pillai M R (2012) A case-control nutrigenomic study on the synergistic activity of folate and vitamin B12 in cervical cancer progression Nutrition and cancer 64550 558

Ramachandrannair R and Parameswaran M (2005) Prevalence of pyridoxine dependent seizures in south Indian children with early onset intractable epilepsy: A hospital based prospective study European journal of paediatric neurology : EJPN : Official journal of the European Paediatric Neurology Society 9 409-413

Rao R H (1983) Glucose tolerance in subclinical pyridoxine deficiency in man The American journal of clinical nutrition 38 440-444

Ravichandran V and Selvam R (1990) Increased lipid peroxidation in kidney of vitamin B-6 deficient rats Biochemistry international 21 599-605

Refsum H, Yajnik C S, Gadkari M, Schneede J, Vollset S E, Orning L, Guttormsen A B, Joglekar A, Sayyad M G, Ulvik A et al. (2001) Hyperhomocysteinemia and elevated methylmalonic acid indicate a high prevalence of cobalamin deficiency in Asian Indians The American journal of clinical nutrition 74 233-241

Rosenberg I H (2012) A history of the isolation and identification of vitamin B(6) Annals of nutrition \& metabolism 61236 238

Samuel T M, Duggan C, Thomas T, Bosch R, Rajendran R, Virtanen S M, Srinivasan K and Kurpad A V (2013) Vitamin B(12) intake and status in early pregnancy among urban South Indian women Annals of nutrition \& metabolism 62 113122

Satyanarayana A, Balakrishna N, Pitla S, Reddy P Y, Mudili S, Lopamudra P, Suryanarayana P, Viswanath K, Ayyagari R and Reddy G B (2011) Status of B-vitamins and homocysteine in diabetic retinopathy: association with vitamin-B12 deficiency and hyperhomocysteinemia PloS one 6 e 26747

Sen A and Kanani S J (2009) Impact of iron-folic acid supplementation on cognitive abilities of school girls in Vadodara Indian pediatrics 46 137-143

Sen S K, Pukazhvanthen P and Abraham R (2008) Plasma Homocysteine, Folate and Vitamin B(12) levels in senile cataract Indian journal of clinical biochemistry : IJCB $\mathbf{2 3}$ 255-257

Shane B (2008) Folate and vitamin B12 metabolism: overview and interaction with riboflavin, vitamin B6, and polymorphisms Food and nutrition bulletin 29 S5-16; discussion S17-19

Sharma S, Sidhu H, Narula R, Thind S K and Nath R (1990) Comparative studies on the effect of vitamin A, B1 and B6 deficiency on oxalate metabolism in male rats Annals of nutrition \& metabolism 34 104-111

Shobha V, Tarey S D, Singh R G, Shetty P, Unni U S, Srinivasan K and Kurpad A V (2011) Vitamin B12 deficiency \& levels of metabolites in an apparently normal urban south Indian elderly population The Indian journal of medical research $134432-439$

Singh R, Kanwar S S, Sood P K and Nehru B (2011) Beneficial effects of folic acid on enhancement of memory and antioxidant status in aged rat brain Cellular and molecular neurobiology 31 83-91

Sivaprasad M, Shalini T, Balakrishna N, Sudarshan M, Lopamudra P, Suryanarayana P, Arlappa N, Ravikumar B P, Radhika M S and Reddy G B (2016) Status of Vitamin B12 and Folate among the Urban Adult Population in South India Annals of nutrition \& metabolism 68 94-102

Smith A D, Kim Y I and Refsum H (2008) Is folic acid good for everyone? The American journal of clinical nutrition $\mathbf{8 7}$ $517-533$

Stanger O (2012) Water Soluble Vitamins Subcellular biochemistry 56

Stene L C, Oikarinen S, Hyoty H, Barriga K J, Norris J M, Klingensmith G, Hutton J C, Erlich H A, Eisenbarth G S and Rewers M (2010) Enterovirus infection and progression from islet autoimmunity to type 1 diabetes: The Diabetes and Autoimmunity Study in the Young (DAISY) Diabetes 59 3174-3180

Strand T A, Taneja S, Kumar T, Manger M S, Refsum H, Yajnik C S and Bhandari N (2015) Vitamin B-12, folic acid, and growth in 6- to 30-month-old children: a randomized controlled trial Pediatrics 135 e918-926

Strand T A, Taneja S, Ueland P M, Refsum H, Bahl R, Schneede J, Sommerfelt H and Bhandari N (2013) Cobalamin and folate status predicts mental development scores in North 
Indian children 12-18 mo of age The American journal of clinical nutrition 97 310-317

Sukla K K and Raman R (2012) Association of MTHFR and RFC1 gene polymorphism with hyperhomocysteinemia and its modulation by vitamin B12 and folic acid in an Indian population European journal of clinical nutrition 66 111-118

Sukla K K, Tiwari P K, Kumar A and Raman R (2013) Low birthweight (LBW) and neonatal hyperbilirubinemia $(\mathrm{NNH})$ in an Indian cohort: Association of homocysteine, its metabolic pathway genes and micronutrients as risk factors PloS one $\mathbf{8}$ e 71587

Tandon S, Moulik N R, Kumar A, Mahdi A A and Kumar A (2015) Effect of Pre-treatment Nutritional Status, Folate and Vitamin B12 Levels on Induction Chemotherapy in Children with Acute Lymphoblastic Leukemia Indian pediatrics $\mathbf{5 2} 385-389$

Taneja S, Bhandari N, Strand T A, Sommerfelt H, Refsum H, Ueland P M, Schneede J, Bahl R and Bhan M K (2007) Cobalamin and folate status in infants and young children in a low-to-middle income community in India The American journal of clinical nutrition 86 1302-1309

Taneja S, Strand T A, Kumar T, Mahesh M, Mohan S, Manger M S, Refsum H, Yajnik C S and Bhandari N (2013) Folic acid and vitamin B-12 supplementation and common infections in 6-30-mo-old children in India: A randomized placebocontrolled trial The American journal of clinical nutrition $98731-737$

Thomas D, Chandra J, Sharma S, Jain A and Pemde H K (2015) Determinants of Nutritional Anemia in Adolescents Indian pediatrics $\mathbf{5 2} 867-869$

van Guldener C (2006) Why is homocysteine elevated in renal failure and what can be expected from homocysteinelowering? Nephrology, dialysis, transplantation : Official publication of the European Dialysis and Transplant Association - European Renal Association 21 1161-1166

Veena S R, Krishnaveni G V, Srinivasan K, Wills A K, Muthayya S, Kurpad A V, Yajnik C S and Fall C H (2010) Higher maternal plasma folate but not vitamin B-12 concentrations during pregnancy are associated with better cognitive function scores in 9- to 10- year-old children in South India The Journal of nutrition 140 1014-1022

Vijayalakshmi R and Bamji M S (1987) Altered glucose metabolism in female rats treated with sex steroids: reversal by excess pyridoxine Indian journal of biochemistry \& biophysics 24 329-335

Vijayalakshmi R, Bamji M S and Ramalakshmi B A(1988) Reduced anaerobic glycolysis in oral contraceptive users Contraception 38 91-97

Vir S C, Singh N, Nigam A K and Jain R (2008) Weekly iron and folic acid supplementation with counseling reduces anemia in adolescent girls: A large-scale effectiveness study in Uttar Pradesh, India Food and nutrition bulletin 29 186194

Wendt A, Stephenson R, Young M, Webb-Girard A, Hogue C, Ramakrishnan U and Martorell R (2015) Individual and facility-level determinants of iron and folic acid receipt and adequate consumption among pregnant women in rural Bihar, India PloS one 10 e 0120404

Wondrak G T and Jacobson E L (2012) Vitamin B6: Beyond coenzyme functions Sub-cellular biochemistry 56 291300

Wu X Y and Lu L (2012) Vitamin B6 deficiency, genome instability and cancer Asian Pacific journal of cancer prevention : APJCP 13 5333-5338

Yaikhomba T, Poswal L and Goyal S (2015) Assessment of iron, folate and vitamin B12 status in severe acute malnutrition Indian journal of pediatrics 82 511-514

Yajnik C S, Deshpande S S, Jackson A A, Refsum H, Rao S, Fisher D J, Bhat D S, Naik S S, Coyaji K J, Joglekar C V et al. (2008) Vitamin B12 and folate concentrations during pregnancy and insulin resistance in the offspring: The Pune Maternal Nutrition Study Diabetologia 51 29-38

Yajnik C S, Deshpande S S, Lubree H G, Naik S S, Bhat D S, Uradey B S, Deshpande J A, Rege S S, Refsum H and Yudkin J S (2006) Vitamin B12 deficiency and hyperhomocysteinemia in rural and urban Indians The Journal of the Association of Physicians of India 54 775782

Yajnik C S, Lubree H G, Thuse N V, Ramdas L V, Deshpande S S, Deshpande V U, Deshpande J A, Uradey B S, Ganpule A A, Naik S S et al. (2007) Oral vitamin B12 supplementation reduces plasma total homocysteine concentration in women in India Asia Pacific journal of clinical nutrition 16 103109

Yanaka N, Koyama T A, Komatsu S, Nakamura E, Kanda M and Kato N (2005) Vitamin B6 suppresses NF-kappaB activation in LPS-stimulated mouse macrophages International journal of molecular medicine 16 1071-1075

Zsengeller Z K, Aljinovic N, Teot L A, Korson M, Rodig N, Sloan J L, Venditti C P, Berry G T and Rosen S (2014) Methylmalonic acidemia: a megamitochondrial disorder affecting the kidney Pediatric nephrology 29 2139-2146. 